\title{
Strategic Management Role on Contemporary Emerging Market - The Female Economy
}

\author{
Rrezarta Gashi, PhD Candidate
}

\author{
European University of Tirana, Albania \\ rrezartag@gmail.com
}

\author{
Doi:10.5901/mjss.2015.v6n3p156
}

\section{Abstract}

Economic power of women in today's is surging solidly whereas creating positive climate on businesses worldwide. Business people make long term plans and tend having bright vision about the future, commonly they look closely about market trends, it's movement and positive changes. Literally, they are pretty aware of female purchasing power, hence, they identify the opportunity of newly emerged market- the females market towards which market responding wisely to their demands and request is prerequisite for survivor. Doing so, strategic management is the best decision being applied getting good chunk of this market that provides high return for every single investment done. Since female make almost half global population converting into the money meaning they make almost $85 \%$ of all purchases made in the world. Taking this fact into account, businesses must make a leap ahead reaching this market and women as main actor in it. Additionally, women are ongoing growing working force, academically and highly educated, in some occasions are better paid than men, have own money for personal and family spending, and unstoppably search for life and work balance achievement. Aforementioned facts strengthens consciousness to whom businesses should focus their managerial and business strategy - straight forward the new market having known that the global biggest market - female market, is everywhere around us. Every strategic movement of businesses having females on focus must move swiftly and prepare business operation upon high and firm demands that in return make businesses more lucrative and give strength for further succeeding. Strategic management consists of actions and organizations to create sustain and highly competitive advantage for businesses, pursuing contemporary trends is an operation engagement and venture that facilitate seizing share into the arising market powered by women.

Keywords: Women, Strategic, Management, Businesses, Market.

\section{Introduction}

Rising power of women as primary international consumer is becoming reality. Her power derives from many sourcesworth to be mentioned is as well her role on managing and leading business positions where she put her private purchasing experience into the action by expressing the way she feels and needs as woman consumer. Contemporary living styles bestowed her at head role of a family which she tries to manage given position by completing professional work, care giving for her children, her husband and other family members, meantime completing the rest of family duties such are chores, for instance. Almost entire spending and family purchases goes thru her hands, so she, woman, is maturing with or without her wish into the position of a major decision maker in a family.

Women are most powerful customers on the planet, influencing or purchasing $85 \%$ of everything businesses make, sell, or offer (Quinlan, Drexler, Chapman, 2010).

Women now earn one trillion dollars a year and their incomes over the past three decades have increased a dramatic $63 \%$ after inflation. This increase in earning power is not result of one big event but has been fueled by a series of important changes in the working place, family and personal lives of women. Women account for roughly $80 \%$ of all consumers buying. The Center for Women's Business Research indicates that businesswomen (working women and female entrepreneurs) are the primary decision makers in households, making $95 \%$ of the purchase decisions. Women now bring more of the household income in the majority of U.S households. In the $55 \%$ of U.S households made up of married couples, Census Bureau survey data indicated that $48 \%$ of the working wives provide at least half of household income. Today they comprise a significant majority of customers for most businesses. So focusing on their preferences is literally big businesses that can dramatically affect a company's sales, make share and profits (Johnson \& Learned, 2004).

Therefore, its power and strong position on market is seemingly obvious which makes woman being targeted as main customer widely from businesses around the globe. Accordingly, vast majority of businesses began shaping management strategies leaning towards main decision maker in order to obtain higher turnover and revenues, 
consequently.

Some reliable and useful tips for businesses about picking the right strategy while it come choosing being focused on female as most important target customer:

Creating products for women isn't about sacrificing one gender to gain the business of another. Ideally, it's about broadening your reach and increasing your revenues by adding more products that appeal to the world's primary shoppers. Once you've got the product right, the next critical step comes into play: make it women want it.

a. Women can help grow flat economy - If you are in a product category or industry that's hit a plateau, focusing on women may help bring in new customers and revenues.

b. Women are key customers to the next generation of customers - if you want children and teenagers to participate in an activity, get their mothers excited about it.

c. Women's participation has a multiplier effect in terms of people and purchases - not only do women bring their friends and family members to companies activities that they're thrilled with, they spend money differently and often more of it, on accoutrements (Brennan, 2011).

Significance of paper relies on strong facts and figures displaying ongoing rising purchasing power of women on markets all around the world - even, from many is referred as newly emerging markets along other existing ones. Obviously, women most recently are counted as core drive on many businesses. Many of businesses initiated strategy alignment towards demands coming from women. Besides, many businesses did not cease just on women demands for goods and services, being aware of their power they spurred and gave chances to many women toping on leading managerial positions in many eminent companies and corporations. Data provided are result for proper and original description of outcomes part of qualitative methods used for completion and representation of this valuable research paper useful for readers who are willing to gain comprehensive knowledge on management strategy and its impact in businesses and economy, as well.

\section{Business Strategy Alignment towards the Female Economy}

Seeing long term opportunities, businesses must search for new and markets. Not always markets abroad or on distanced countries may be counted as thriving ones. The emergence of the female economy holds the potential for creation of vast wealth- the $\$ 2$ trillion of consumer spending now controlled by women could climb to as high as \$ 28 trillion in the next several years. Women's trillion in total earning could grow to as much as $\$ 18$ trillion on the same period. Women find themselves caught in an upward spiral. If they and their families are to continue to achieve higher levels of prosperity, health, education, and accumulated wealth, they have virtually no choice but to work full-time. Although the status of women has changed, much of the world seems not to have noticed or adjusted the new reality. For example, the great majority participates in the workforce, but these women still do most of households' chores. What's more, although women control the spending in most categories of consumers goods- including food, clothing, personal care, households goods and services, travel, healthcare, financial services and education- too many companies continues to make poorly conceived products, offer services that up way too much for women's precious time, and serve up outdated marketing narratives women as stereotypes. Further the female economy will challenge corporate leaders and managers to reexamine their human resources practices-how they recruit, select, develop, integrate, retain, and provide support to their people and how they help nurture and facilitate healthy work-life balance.(Silverstein \& Sayre, 2009).

A fact drawn from the research of market which makes businesses being aware of new demands is the plus size women as target market in US, as a sample. The average woman is a size fourteen and the number isn't expected to change anytime soon. Women of all sizes want beautiful clothes, elegant bridal gowns, lovely pro dresses, fashionable shoes, and cool workout gear (Brennan, 2011). Merely, as businesses get deeper into the women analyses figures out that number of plus sized women are those that hold purses of economy whose earnings are solid and their buying decisions are also huge; consequently strategy alignment towards these category of buyers brings higher revenues with little changes of shifting the supply according to demands.

\section{Leading Strategy - Women on Top of Business a New Leadership Model}

It's often been said that women are the most underutilized asset in the world studies have shown that the economic inclusion of women is fundamental to reducing gender inequality and spurring overall growth. Women's economic participation has been shown to have a multiplier effect: the economic empowerment of one women ripples meaningfully to her children and family-even to entire communities and nations (Blomqvist, Chastain, Thickett, Unnikrishnan, Woods, 
2014).

In a business environment where competition, employees, and teams are becoming more global and stakeholders group are becoming more global, and stakeholder groups are more diverse, what are the characteristics of an effective business leader in the $21^{\text {th }}$ century and where do women fit into this picture-some raise the question? Anyway, it has been shown that despite the fact that some archaic thoughts still retain on the assumptions of adage effected stories that business should and could be led mainly by men which in practice proved to be not totally right. Nowadays in many companies engagement of women in leading positions and their participation on decisive decision making on multiple field of various businesses is proof of abilities expressed from women on leading businesses. Today female executives from range of multinational companies are taking adaptive approach in order to sustain performance and, in turn being as adaptive as they could in new leadership roles. The model represented from leading woman is indentified the differentiating characteristics of those leaders who will thrive in a $21^{\text {st }}$ century world: navigate-embrace global uncertainty and chart a clear course: empathize - achieve influence and authority through networking: self-correct- unlearn outmoded success models: and win and win - deliver sustainable success to company and stakeholders. Above all as soon as a company appoints a woman on top of a company- highly educated and experienced as well, one thing is clear companies will have to profoundly reshape the way they manage their talent and develop their leaders. (Torres \& Caye, 2011).

Despite numerous cases well known internationally where women successfully direct and manage companies and corporate in billion and trillion revenues, there are some even argue and slightly suspect about that young women may face unique challenges in asserting and developing a leadership style. Some struggle with managing style, some may perceive them as not acting feminine enough, but if they act in stereotypically feminine way they aren't seen as strong leaders. Leadership coaches encourage women to take charge of their office image by showcasing their workplace activities in thoughtful ways, such as leading presentations at meetings. When the company has new project in the works, women should suggest how their research and skills contribute on nurturing the ideas for further achievements since they ought to unveil knowledge of being part of heading staff which expectances for goals set to be achieved are on their hand to put them in practice. (The Wall Street Journal, 2009).

In many circumstances women attempt to reveal leadership abilities and knowledge even though are seen or perceived that lag behind the men on leading positions. Achieving success and being on top, they should doubtlessly be encouraged and pushed forward in one way or another. In despite perception or culture the way women are seen, there is opportunity for plenty of business which can surely positively change the course of operation selecting a woman heading the company, while it's been attested a brilliant choice practiced in many corporation around the globe, i.e. Pepsi Co, Revlon, Wal-Mart Stores, Intel, General Motors, Morgan Chase, Hewlett-Packards, Oracle, DuPont, Procter \& Gamble are just some of the prosperous international companies and corporations samples of roles models head from women.

Women have made great progress in business. They make up more than half the workforce and are increasingly occupying management and senior leadership positions. The "playing field" has become more level in many industries and countries and women are able to compete directly as never before. Some companies are actively recruiting women for their boards. They are building programmers to move more women into the management ranks and leadership pipeline. But there is still progress to be made.

A few facts to consider:

- Companies and some governments are increasingly interested in setting gender balance quotas,

- Many companies want more diversity in the decision-making, or a more participative style of leadership,

- Customers are increasingly female and expect to be able to deal with other women,

- There is a shortage of qualified management talent to move into management roles for the future,

- Women are an "untapped resource",

- Female university graduates outnumber males in most countries ${ }^{1}$.

Moreover, throughout Europe countries are passed legislations about improving representation of women on corporate boards. Recently the German legislation requires improving representation of women on board of corporation giving them rights holding $30 \%$ of supervisory seats, which law will be enforced starting from next year. Currently, fewer than 20 percent of the seats on corporate boards in Germany are held by women, while some of the biggest multinational companies in the world are based here, including Volkswagen, BMW and Daimler - the maker of Mercedes-Benz vehicles - as well as Siemens, Deutsche Bank, BASF, Bayer and Merck. Norway was the first in Europe to legislate

1 "Women in Leadership and Management" http://www.mce-ama.com/strategy-execution-expertise/women-managers/ 
boardroom quotas, joined by Spain, France and Iceland, which all set their minimums at $40 \%$. Italy has a quota of onethird, Belgium of 30 percent and the Netherlands a 30 percent nonbinding target. Britain has not legislated boardroom quotas, but a voluntary effort, known as the $30 \%$ Club, has helped to substantially increase women's representation. The group, founded by Helena Morrissey, a money manager, has used persuasion to help double the percentage of women on the boards of major British companies since 2010, to $23 \%$ (Smale \& Miller, 2015).

\section{Long Term Strategy - Focus on Power of Women in Business and Economy}

Aforementioned role of women on top of corporations and companies could be counted as a step further leaping ahead towards higher achievements and competition advantages; moreover it's one among many management strategies picked which build company or business prosperity at the same time. Range of management strategies where female is main target to be pursued and whose power can be divulged in business and economy, as whole, can be built on long term -strategies which can rely mainly on the female as crucial factor on contemporary business world which is driven from.

Since purpose of businesses is retaining some profit out of operation, surviving amidst competition should be found a path to run on. Finding a proper way not just to survive but also to make some extra profit and being as lucrative as possible, focusing on newly, as some call it, emerging market - in which women conducts majority of this economy. Shifting one business strategy to something new, isn't easy pattern as it seem. Prior to making decision doing so, getting aligned with market demands, deep research about is highly necessary. Data and information collection will easy attempts getting straightforward reaching target market. Power of women into the global economy market is firmly rising day in day out.

In the United States, women make 80 percent of discretionary purchases, including 90 percent of food and 55 percent of consumer electronic purchases ${ }^{2}$. Women may be the primary purchasers for their households. Far more women than men are worried about their economic security. The competing tension between saving and spending is not unique to women, but because women are the primary consumers in America any signs of increasing confidence among women may signal a strengthening economy. The role that women have played in the economy has dramatically changed in the last 50 years. Having once provided what was viewed as supplementary income, today, women earn 45 percent of all household income and over seven million families rely mainly or solely on the woman's income to survive (Keil, 2009).

A research conducted from Index of Women's Economic Opportunity in the 2012, "women are the key driver of economic growth." research has shown that in the United States alone, women have added 2 percentage points per year to the overall economic growth. Similar or even better numbers have been seen in numerous countries all around the world. These studies only account for women in developed countries. However, the same improvements can be seen in developing countries with education and empowerment for every single female. Tapping into the most prominent unused workforce in the world would have undoubtedly huge, positive impacts on the global economy. The WEO is a great way to see clear and positive results on how improving our global economy can become a reality. (Youngs).

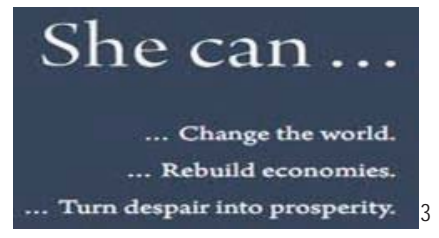

If women hadn't dramatically increased how much time they spend working for pay outside the home since the late 1970s, gross domestic product (GDP) would have been about 11 percent lower in 2012, according to a new report from the Center for American Progress (CAP). That's nearly twice the contribution to GDP from information, communications, and technology-producing industries that year. Women's contribution to GDP also translates to more than $\$ 1.7$ trillion in greater output, "roughly equivalent to combined U.S. spending on Social Security, Medicare, and Medicaid in 2012," the report notes (Covert, 2014).

But there's another trend that has led to sharply higher economic output, and one that goes largely overlooked.

2 The Economist : "Hello Girls" http://www.economist.com/node/13278440

${ }^{3}$ http://notenoughgood.com/2012/04/womens-economic-opportunity/ 
That is the flood of women into the full-time workforce: Since 1979, the proportion of working-age women with a full-time job has surged to 40.7 percent from 28.6 percent. For mothers, the effect is even more striking: The proportion has climbed to 44.1 percent from 27.3 percent (Lowrey, 2015).

On basis of data and information gathered from research done as part of qualitative analyses methods used for completion of paper, I conclude that extraction of important values are foundation of facts that businesses should turn head and businesses strategy towards women aligning product and service providing based on demands targeting the high demands as main potential for market segmentation.

\section{Recommandation}

Businesses in general in some cases unintentionally may omit the women from not appointing or selecting her in crucial positions. Aware that this is not a mere justification but the "masculine" culture reign or it's inherited in many countries wide. Topic of women and her accurate brain potential is topic of discussions in many conferences and economic journals - meanwhile it was a topic which took place and comprehensively discussed at The Wall Street Journal dedicated to Women in Economy. Among other topics was also the one talking about moving forwards the industry with women on top of it, so from this debate five golden recommendations derived as result. Recommendation obtained below indisputably show that every company can improve his market position and even gain more market share with little efforts of making slightly changes which could be characterized as wise management strategies for future goal attainments.

After each individual industry-focused group presented its priorities, the full task force ranked all the priorities, in order of their relative urgency and importance. Here's a look at the top five priorities, as voted by the entire task force.

\subsection{P\&L Leadership}

Companies should establish a program to train and encourage women to take leadership positions that involve profit-and loss expertise specifically, and enable them to transition into these roles. Companies should establish specific targets and incentives to this end.

\subsection{Leverage C-Suite Power}

Hold the CEO accountable for hiring women in the top jobs with equal pay. Use metrics and scorecards to track women's promotions and positions, and if women aren't promoted, explain why not. Require a diverse slate of candidates for highlevel jobs. Expect a balance of men and women at the decision-making table, including the board.

\subsection{Promote Women on Potential}

Women should be equally considered for promotion on their potential as are men. Companies need to identify talented women early and nurture them. Employers should create incentives for female sponsorship, tying success to mechanisms such as compensation, goal achievement and performance evaluation.

\subsection{Mentors and Sponsors}

Develop more industry wide and company-specific programs for both mentorship and sponsorship. Tie sponsorship goals to pay or career advancement. Such programs should include succession planning and "co-mentoring," which allows advice to flow from junior to senior levels. Involve men and women.

\subsection{Strong Talent-Management Programs}

Recruit outside normal channels and leverage diverse networks. Take risks on high-potential women by rotating them through different positions and giving them exposure to senior leadership. Provide training in effective communication and strategic thinking. Foster entrepreneurial culture, including a more flexible work/life environment. (The Wall Street Journal, 2011). 


\section{Conclusion}

Women's influence on market, as seen from many marketers, creates a frame that comprises purchasing power, decision making, personal earnings and control over household wallet which literally means control upon almost entire family spending. Woman is also considered a witty manager of household economy whilst many businesses based on this issue are appointing her on top of companies to manage and led businesses in many cases some big corporations as she does manage her family.

Increasing power of women is distinguished worldwide. Her role on world economy is incremental. Most of the companies try to get closer and study behavior of female aiming to align and shift business strategy according to her requests and demands being knowledgeable the rise which can experience those businesses in case of make women likable products and services. In sum, picture of women can be framed allegedly as: powerful, decision makers, wallet keepers, big spender and key factor on economy, hence, clue for business success should easily get - let pursue her.

\section{References}

Blomqvist, M., Chastain, E., Thickett, B., Unnikrishnan, Sh., Woods, W. (2014). "Bridging the Entrepreneurship Gender Gap: The Power of Networks." Retrieved on January 10, 2015,from: https://www.bcgperspectives.com/content/articles/business_social_sector_ investing_impact_bridging_entrepreneurship_gender_gap/

Brennan, B. (2011). "Why She Buys- The New Strategy For Reaching The World's Most Powerful Consumers" Crown Publishing Group, New York, USA.

Covert, B. (2014). "The Economy is 11 Percent Bigger Thanks To Women's Work" Retrieved on February 23, 2015 from: http://thinkprogress.org/economy/2014/04/16/3427220/women-work-hours-gdp/

Johson, L. \& Learned, A. (2004). "Don't think Pink: what really makes women buy-and how to increase your share f this crucial market" AMACOM-American Mangement Asociation. USA.

Keil, J. (2009). "Women, the Recession, and the Impending Economic Recovery - An Exploration of Women's Attitudes Toward Debt, Risk, and Consumption." Retrieved on January 2015 from: http://gbr.pepperdine.edu/2010/08/women-the-recession-and-theimpending-economic-recovery

Lowrey, A. (2014). "How Working Women Help the Economy". The New York Times. Retrieved on December 20,2014, from: http://economix.blogs.nytimes.com/2014/04/15/how-working-women-help-the-economy/?_r=1

MCE "Women in Leadership and Management-More Companies are Recruiting More Women for Management and Board Roles." Retrieved on February 18,2015 from: http://www.mce-ama.com/strategy-execution-expertise/women-managers/

Quinlan, L.M. (2003). "Just Ask a Woman: cracking the code of what women want and how they buy" Published by John WILEY \& Sons, Inc, Hoboken, New Jersey. USA.

Quinlan, L.M., Drexler, J., \& Chapman, T. (2010). "What she's not telling you: why women hide the whole truth and what marketers can do about it" Just Aks a Women Media, New York, USA.

Silverstein, M. \& Sayre, K. (2009). "Women Want More: How to capture your share of the world's largest, fastest-growing market" The Boston Consulting Group, New York,NY 10022. USA.

Smale, A. \& Miller, C. C. (March 06, 2015). "Germany Sets Gender Quota in Boardrooms". Retrieved on March 07, 2015, from: http://www.nytimes.com/2015/03/07/world/europe/german-law-requires-more-women-on-corporate-boards.html

The Wall Street Journal (2009). "How Can Young Women Develop a Leadership Style?" Retrieved on December 21, 2014 from: http://guides.wsj.com/management/developing-a-leadership-style/how-can-young-women-develop-a-leadership-style/tab/print/

The Wall Street Journal (April 11, 2011). "Industry by Industry: How to Move Forward-The Top Five Recommendations" Retrieved on February 17,2015 from: http://www.womeninecon.wsj.com/special-report.pdf

Torres, R., \& Caye, J-M. (2011). "View from Deauville: Business Ideas for Long-Term Solutions." Retrieved on January 14, 2015, from: https://www.bcgperspectives.com/content/commentary/engagement_culture_leadership_view_from_deauville_leadership_for_21 st_centuryl

Young, K. "Using the Index of Women's Economic Opportunity to Improve the Global Economy" Retrieved on January 28, 20155 from: http://notenoughgood.com/2012/04/womens-economic-opportunity/ 